\title{
Diabetic Embryopathy Susceptibility in Mice Is Associated with Differential Dependence on Glucosamine and Modulation of High Glucose-Induced Oxidative Stress
}

\author{
Jin Hyuk Jung $\mathbb{D}$ and Mary R. Loeken *(D) \\ Section on Islet Cell and Regenerative Biology, Joslin Diabetes Center, Department of Medicine, \\ Harvard Medical School, Boston, MA 02215, USA; jungjh@skinresearch.or.kr \\ * Correspondence: mary.loeken@joslin.harvard.edu; Tel.: +1-617-309-2525
}

check for updates

Citation: Jung, J.H.; Loeken, M.R. Diabetic Embryopathy Susceptibility in Mice Is Associated with Differential Dependence on Glucosamine and Modulation of High Glucose-Induced Oxidative Stress. Antioxidants 2021, 10, 1156. https://doi.org/10.3390/antiox10081156

Academic Editors: Giulia Guerriero and Gerardino D'Errico

Received: 31 May 2021

Accepted: 18 July 2021

Published: 21 July 2021

Publisher's Note: MDPI stays neutral with regard to jurisdictional claims in published maps and institutional affiliations.

Copyright: (c) 2021 by the authors. Licensee MDPI, Basel, Switzerland. This article is an open access article distributed under the terms and conditions of the Creative Commons Attribution (CC BY) license (https:/ / creativecommons.org/licenses/by/ $4.0 /)$.

\begin{abstract}
The high $\mathrm{K}_{\mathrm{M}}$ glucose transporter, GLUT2 (SLC2A2), is expressed by embryos and causes high rates of glucose transport during maternal hyperglycemic episodes in diabetic pregnancies and causes congenital malformations (diabetic embryopathy). GLUT2 is also a low $\mathrm{K}_{\mathrm{M}}$ transporter of the amino sugar, glucosamine $(\mathrm{GlcN})$, which enters the hexosamine biosynthetic pathway (HBP) and provides substrate for glycosylation reactions. Exogenous GlcN also increases activity of the pentose phosphate pathway (PPP), which increases production of NADPH reducing equivalents. GLUT2transported GlcN is inhibited by high glucose concentrations. Not all mouse strains are susceptible to diabetic embryopathy. The aim of this study was to test the hypothesis that susceptibility to diabetic embryopathy is related to differential dependence on exogenous GlcN for glycosylation or stimulation of the PPP. We tested this using murine embryonic stem cell (ESC) lines that were derived from embryopathy-susceptible FVB/NJ (FVB), and embryopathy-resistant C57Bl/6J (B6), embryos in the presence of low or high glucose, and in the presence or absence of GlcN. There were no significant differences in Glut2 expression, or of glucose or GlcN transport, between FVB and B6 ESC. GlcN effects on growth and incorporation into glycoproteins indicated that FVB ESC are more dependent on exogenous GlcN than are B6 ESC. GlcN stimulated PPP activity in FVB but not in B6 ESC. High glucose induced oxidative stress in FVB ESC but not in B6 ESC. These results indicate that FVB embryos are more dependent on exogenous GlcN for glycosylation, but also for stimulation of the PPP and NADPH production, than are B6 embryos, thereby rendering FVB embryos more susceptible to high glucose to induce oxidative stress.
\end{abstract}

Keywords: diabetic pregnancy; hexosamine biosynthesis; glucose transport; embryo metabolism

\section{Introduction}

Maternal diabetes that is present prior to pregnancy (pregestational diabetes) significantly increases risk for congenital malformations, a diabetic complication known as "diabetic embryopathy"; in both human fetuses and in animal models, neural tube defects NTDs are among the most common that occur [1-4]. Using a mouse model of diabetic pregnancy, we have shown that maternal hyperglycemia, through high rates of glucose transport into embryo cells via the high $\mathrm{K}_{\mathrm{M}}$ glucose transporter, GLUT2 (SLC2A2), is responsible for diabetes-induced NTDs [5,6]. Several studies using animal models have shown that maternal diabetes-induced oxidative stress is central to diabetic embryopathy [7-12]. Several studies from our lab have shown that high glucose-induced oxidative stress inhibits gene expression that is required for neural tube closure and inhibition of apoptosis, thereby causing NTDs [6,12-14].

GLUT2 is not likely to function as a physiological glucose transporter for the embryo when mothers are not hyperglycemic, because the GLUT2 $\mathrm{K}_{\mathrm{M}}$ for glucose (approximately $16 \mathrm{mmol} / \mathrm{L})$ is significantly higher than normal blood glucose concentrations $(5.5 \mathrm{mmol} / \mathrm{L})$ and embryos also express the low $\mathrm{K}_{\mathrm{M}}$ (approximately $5.5 \mathrm{mmol} / \mathrm{L}$ ) glucose transporters, 
GLUT1 and GLUT3, which would transport glucose more efficiently than GLUT2 during euglycemia $[15,16]$. We noticed that Glut2-deficient embryos have a survival disadvantage compared to their wild type littermates [5], suggesting that GLUT2 serves an important survival function during normal embryogenesis. GLUT2 is also a low $\mathrm{K}_{\mathrm{M}}(0.8 \mathrm{mmol} / \mathrm{L})$ glucosamine (GlcN) transporter [17]. We recently showed that GlcN stimulates proliferation of embryonic stem cells (ESC) in a GLUT2-dependent manner [18]. Upon transport and phosphorylation, GlcN enters the hexosamine biosynthetic pathway (HBP), which provides substrates for glycosylation reactions. GlcN-6- $\mathrm{PO}_{4}$ can also be synthesized from fructose-6- $\mathrm{PO}_{4}+$ glutamine; however, uptake of exogenous $\mathrm{GlcN}$ increases substrates for glycosylation, while decreasing entry of fructose-6- $\mathrm{PO}_{4}$ and glutamine into the HBP, thereby increasing substrates for the pentose phosphate pathway (PPP), glycolysis, and the tricarboxylic acid (TCA) cycle [18]. GLUT2-transported glucose inhibits uptake of GlcN [18]. Therefore, some of the adverse effects of maternal hyperglycemia to induce malformations might be not only due to increased glucose uptake and metabolism, but also to insufficient GlcN uptake and metabolism.

We previously reported that C57Bl/6J (B6) embryos, unlike FVB/NJ (FVB) embryos, are resistant to NTDs induced during diabetic pregnancy, despite similar levels of maternal hyperglycemia; this is correlated with failure to inhibit expression of Pax3, which is required for neural tube closure, in B6 embryos of diabetic mothers [19]. Thus, strain background differences may be useful to reveal metabolic pathways that are essential for diabetic embryopathy. Because GLUT2 confers susceptibility to hyperglycemia-induced NTDs [5], and high glucose concentrations significantly inhibit GLUT2-transported GlcN [18], we hypothesized that the differences in susceptibility to diabetic embryopathy of FVB and B6 embryos is due to differential dependence on exogenous (maternal) GlcN to support hexosamine biosynthesis, promote growth, and regulate oxidative stress. Thus, when embryos are exposed to elevated glucose concentrations, decreased GlcN transport could adversely affect development of FVB, but not in B6, embryos.

This hypothesis cannot be tested in vivo because, while maternal GlcN levels can be raised, they cannot be lowered or eliminated. Instead, here we tested whether differential GlcN metabolism is correlated with susceptibility to diabetic embryopathy, using ESC that were derived from FVB or B6 blastocysts in low glucose media (LG-ESC) that retain expression of functional GLUT2 transporters [20,21]. We first tested whether FVB and B6 embryos exhibit differential susceptibility to NTDs specifically in response to maternal hyperglycemia, as they do in response to maternal diabetes, which is necessary in order to validate the use of LG-ESC derived from these strains to study effects of glucose and GlcN on metabolic pathways associated with diabetic embryopathy. We next compared expression of Glut 2 by the two strains, and studied transport of the HBP substrates, glucose, glutamine, and GlcN, as well as utilization of glutamine or GlcN for incorporation into glycoproteins. Finally, we tested the effects of GlcN on growth of pluripotent ESC colonies by the two cell lines, as well as activity of the PPP and markers of oxidative stress.

\section{Materials and Methods}

\subsection{Animals}

All animal procedures were approved by the Institutional Animal Care and Use Committee (IACUC) of the Joslin Diabetes Center. Six-week-old female and male FVB and B6 mice were purchased from the Jackson Laboratory (Bar Harbor, ME, USA) and were maintained on a 12-h light-dark cycle with free access to food (PicoLab Mouse Diet 20) and water. Nondiabetic female mice were housed with nondiabetic males of the same strain and were checked daily for copulation plugs. Noon on the day that a copulation plug was found was determined to be embryonic day (E) 0.5 . To induce hyperglycemia $(>16.65 \mathrm{mmol} / \mathrm{L})$ during a 9-h period on E7.5, which has previously been shown to replicate the embryopathic effects of diabetic pregnancy, pregnant mice were injected with $2 \mathrm{~mL}$ of $12.5 \%$ glucose in phosphate buffered saline (PBS) on E7.5 at approximately hourly 
intervals from 9:00 a.m.-5:00 p.m. as described [6]. Embryos were dissected from uteri on E7.5 or 10.5 .

\subsection{Culture of FVB and B6 LG-ESC}

Murine ESC that were isolated in low glucose $(5.5 \mathrm{mmol} / \mathrm{L})$ Dulbecco's modified Eagle medium (DMEM) from FVB and B6 blastocysts (FVB LG-ESC and B6 LG-ESC) [20,21] were grown in the absence of a feeder layer on culture dishes coated with $0.1 \%$ gelatin, in incubators containing $5 \% \mathrm{O}_{2}$ and $5 \% \mathrm{CO}_{2}$ (balance $\mathrm{N}_{2}$ ) as described [18,21]. ESC were induced to differentiate into neuronal precursors as previously described [21,22], using either low or high glucose $(17.5 \mathrm{mmol} / \mathrm{L})$ media during selection of neuronal precursors from embryoid bodies [21]. All cultures were performed in triplicate.

\subsection{RT-PCR Assays}

Total RNA was extracted using TRIzol reagent (Thermo Fisher Scientific, Waltham, MA, USA). Two hundred ng RNA were reverse transcribed in quadruplicate using the High-Capacity cDNA Reverse Transcription Kit (Thermo Fisher Scientific). Real-time PCR was performed using TaqMan PCR Master Mix (Thermo Fisher Scientific) and primers and VIC-labeled probe to detect $18 \mathrm{~S} r R N A$ (Thermo Fisher Scientific) as the normalization control as described [12]. Primers and FAM-labeled probe for Pax 3 cDNA were previously reported [12]. Primers and FAM-labeled probe for Glut2 cDNA were obtained from Thermo Fisher Scientific.

\subsection{Immunoblot Assays}

Thirty micrograms of whole cell protein extracts were analyzed by immunoblot as described [23]. Sources and dilutions of primary and secondary antibodies used to detect GLUT1, GLUT2, GLUT3, and $\beta$-ACTIN were as reported previously [18]. The glutamine transporters ASCT2, LAT1, SNAT1, and SNAT5 were detected with rabbit antiASCT2/SLC1A5 (1:500, Abcam, Cambridge, MA, USA), rabbit anti-LAT1 (1:1000, Santa Cruz Biotechnology, Dallas, TX, USA), rabbit anti-SNAT1/SLC38A1 (1:200, Abcam), and goat anti-SNAT5/SLC38A5 (1:100, Santa Cruz Biotechnology), respectively. Secondary antibodies were as reported previously [18] or donkey anti-goat IgG HRP-coupled (1:3000, Santa Cruz Biotechnology). Secondary antibodies were detected by Western Lightning Plus-ECL (Thermo Fisher Scientific) and exposure to X-ray film.

\subsection{Alkaline Phosphatase Staining}

Cells were cultured for 4 days, then colonies were stained for alkaline phosphatase (AP) using Fast Red TR salt and Naphthol (both from Sigma-Aldrich, St. Louis, MO, USA) as described [18] and then AP+ colonies in culture dishes were counted.

\subsection{Glucosamine, 2-Deoxy-D-Glucose, and Glutamine Transport Assays}

Transport of ${ }^{3} \mathrm{H}-\mathrm{GlcN}$ and the fluorescent 2-deoxy-D-glucose analog, 2-NBDG, by FVB and B6 LG-ESC were measured as described [17,18,21]. Transport of ${ }^{3} \mathrm{H}$-glutamine was measured as described for ${ }^{3} \mathrm{H}-\mathrm{GlcN}$ transport $[17,18]$ except that cells were grown for 2 days in glutamine-free media supplemented with $200 \mu \mathrm{mol} / \mathrm{L}$ or $4 \mathrm{mmol} / \mathrm{L}$ glutamine + $0.8 \mathrm{mmol} / \mathrm{L} \mathrm{GlcN}$. Cells were incubated in buffer containing $5 \mathrm{mmol} / \mathrm{L}$ 2-deoxy-D-glucose, $200 \mu \mathrm{mol} / \mathrm{L}$ or $4 \mathrm{mmol} / \mathrm{L}$ glutamine containing 0.5 or $10 \mu \mathrm{Ci} 3 \mathrm{H}$-glutamine, respectively, $+0.8 \mathrm{mmol} / \mathrm{L} \mathrm{GlcN}$, for $20 \mathrm{~min}$.

\subsection{Glycoprotein Detection}

Total N-glycosylated proteins were detected by electrophoresis of $10 \mu \mathrm{g}$ cell extract on a $10 \%$ polyacrylamide gel, followed by periodic acid-Schiff (PAS) staining using a Pierce ${ }^{\mathrm{TM}}$ Glycoprotein Staining kit (Thermo Scientific, Waltham, MA, USA). Gels were scanned and bands were quantified using Adobe Photoshop CS5.1 software. Total O-GlcNAcylated proteins were identified by immunoblot as described [13]. Incorporation of glutamine or 
GlcN into total $\mathrm{O}$ - and $\mathrm{N}$-glycosylated proteins was assayed by metabolic labeling of wheat germ agglutinin (WGA)-precipitable protein with ${ }^{3} \mathrm{H}$-glutamine or ${ }^{3} \mathrm{H}-\mathrm{GlcN}$. Briefly, ${ }^{3} \mathrm{H}$ glutamine labeling was performed by culturing cells for 2 days using low glucose DMEM (which contains $4 \mathrm{mmol} / \mathrm{L}$ glutamine) $+0.8 \mathrm{mmol} / \mathrm{L} \mathrm{GlcN}$, then media were replaced with the same media containing $2 \mu \mathrm{Ci} / \mathrm{mL}^{3} \mathrm{H}$-glutamine and cultured for 2 additional days. ${ }^{3} \mathrm{H}-\mathrm{GlcN}$ labeling was performed by culturing cells in low glucose media (which contains $4 \mathrm{mmol} / \mathrm{L}$ glutamine) for 2 days, then media was replaced with media containing $0.8 \mathrm{mmol} / \mathrm{L} \mathrm{GlcN}+2 \mu \mathrm{Ci} / \mathrm{mL} 3 \mathrm{H}-\mathrm{GlcN}$ and cultured for 2 additional days. At the end of culture, cells were washed with cold PBS, scraped to remove them from culture dishes, sonicated, and then glycoproteins were isolated by adsorption to WGA-agarose beads (Thermo Scientific, Waltham, MA, USA) following the manufacturer's instructions.

\subsection{Glucose-6- $\mathrm{PO}_{4}$ Dehydrogenase (G6PD) Assay \\ G6PD activity was assayed after $48 \mathrm{~h}$ of culture $+0.8 \mathrm{mmol} / \mathrm{L} \mathrm{GlcN}$ as described $[18,24,25]$.}

\subsection{Malondialdehyde Assay}

Cells were cultured in low glucose media. After $40 \mathrm{~h}$, media were replaced with low or high glucose media and cultured for an additional $8 \mathrm{~h}$. Malondialdehyde was assayed by thiobarbituric acid reactivity as described [21].

\subsection{Statistical Analyses}

Data were analyzed by two-tailed Student's t-test, by one- or two-way ANOVA followed by Tukey's multiple comparisons test, using GraphPad Prism software v. 8 (San Diego, CA, USA). A $p$ value $<0.05$ was used as statistically significant.

\section{Results}

\subsection{Differential Susceptibility of FVB and B6 Embryos and LG-ESC to the Adverse Effects of High Glucose}

We previously showed that transient maternal hyperglycemia $(\geq 14 \mathrm{mmol} / \mathrm{L})$ on E7.5 is necessary and sufficient to induce NTDs in embryos of mouse strains that are susceptible to diabetic embryopathy [6]. In order to validate the use of LG-ESC derived from mouse strains that differ in susceptibility to diabetic embryopathy as a model to understand whether this differential embryopathy susceptibility is related to GlcN uptake or metabolism, we first tested whether B6 embryos, which are resistant to NTDs induced by diabetic pregnancy, were resistant to NTDs specifically induced by maternal hyperglycemia in the absence of other metabolic disturbances associated with diabetes. Mean blood glucose levels were significantly and similarly increased by glucose injections over a $9-\mathrm{h}$ period on E7.5 ( $>21 \mathrm{mmol} / \mathrm{L}$ ) in both FVB and B6 dams (Figure 1A). However, maternal hyperglycemia significantly increased NTDs only in FVB embryos (Figure 1B). There were no differences in expression of Glut2 mRNA during induction of the neural tube (E7.5, Figure 1C) between FVB or B6 embryos that would explain differences in susceptibiltiy of FVB and B6 embryos to hyperglycemia-induced NTDs.

We next tested whether LG-ESC derived from FVB and B6 blastocysts cultured in high glucose media replicate the differential susceptibility of embryos of these strains to inhibition of Pax3 expression, which occurs in response to maternal diabetes and hyperglycemia and is associated with NTDs in FVB, but not B6 embryos [19]. Expression of Pax3 was induced upon differentiation of FVB and B6 LG-ESC to neuronal precursors, but high glucose significantly inhibited Pax3 expression only by FVB LG-ESC-derived neuronal precursors (Figure 1D,E). There was no significant difference in Glut2 expression by FVB or B6 LG-ESC (Figure 1F). The differential susceptibility of embryos of these strains to the inhibitory effects of high glucose culture on Pax3 expression, and lack of differences in Glut2 expression, indicate that FVB and B6 LG-ESC can be used to study whether the strain differences in susceptibility to diabetic embryopathy are related to differences in GlcN transport or metabolism. 

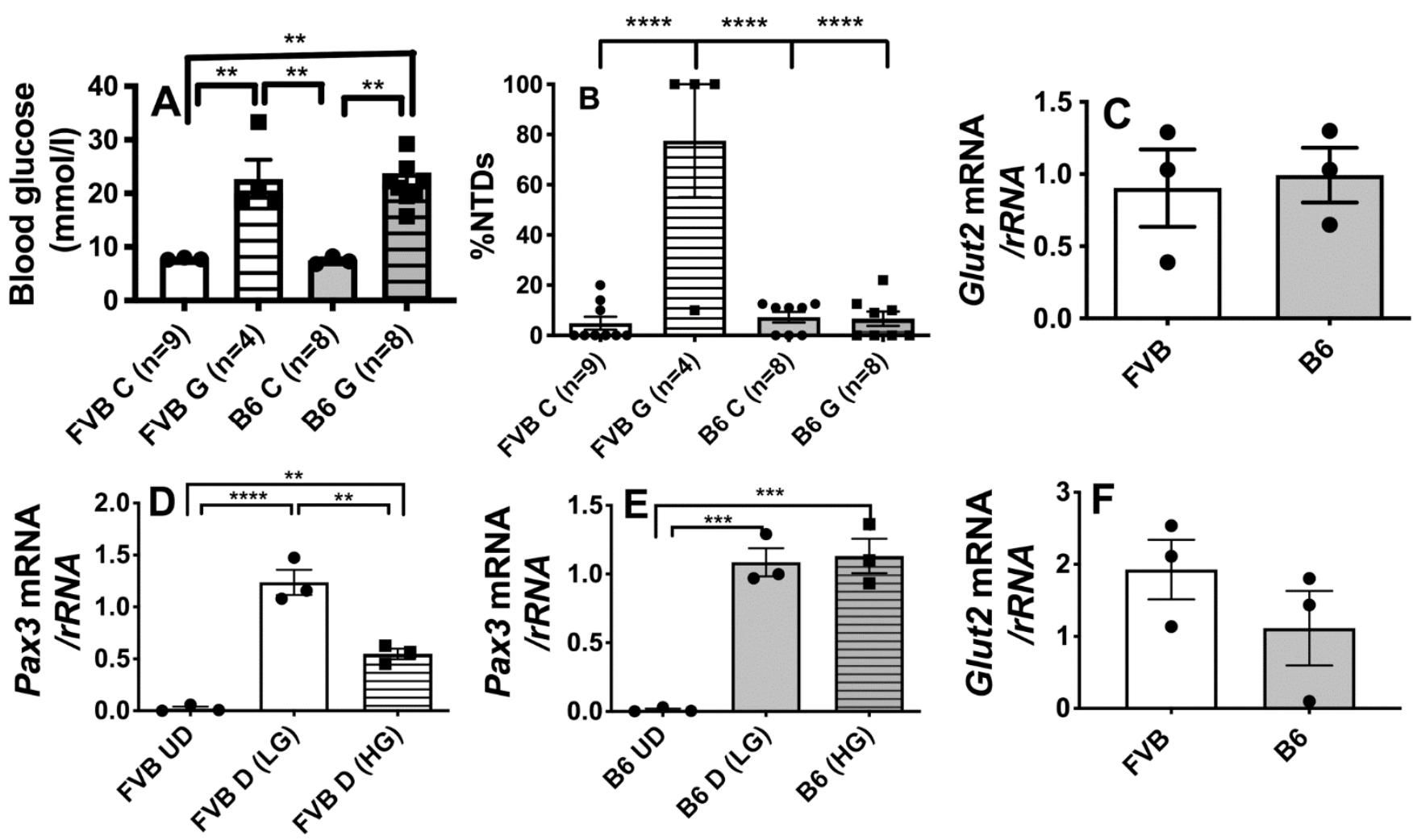

Figure 1. Differential effects of maternal hyperglycemia or high glucose culture on FVB/NJ (FVB) and C57Bl/6J (B6) embryos and ESC. (A) Average hourly blood glucose levels of pregnant control (C) or transiently hyperglycemic from glucose injection (G) FVB or B6 dams on embryonic day (E) E7.5 ( $n=4-9$ litters/treatment group). (B) Percent of embryos with neural tube defects (NTDs) per litter on E10.5 from control or hyperglycemic dams shown in A. (C) Glut2 expression by E7.5 FVB or B6 embryos ( $n=3$ litters each) as determined by real-time RT-PCR of Glut2 mRNA normalized to $r R N A$. (D) Pax3 expression by undifferentiated (UD) or differentiating neuronal precursors (D) FVB LG-ESC cultured in low $(5.5 \mathrm{mmol} / \mathrm{L})$ or high $(17.5 \mathrm{mmol} / \mathrm{L})$ glucose media during selection of neuronal precursors as determined by real-time RT-PCR ( $n=3$ replicate culture dishes). (E) Pax3 expression by B6 LG-ESC cultured and analyzed as in panel D. (F) Glut2 expression by undifferentiated FVB or B6 LG-ESC as determined by real-time RT-PCR. Data shown are means \pm SEM. Data in panels A, B, D, and E were analyzed by one-way ANOVA followed by Tukey's multiple comparisons test. Data in panels $\mathrm{C}$ and F were analyzed by Student's t-test. ${ }^{* *} p<0.01 ;{ }^{* * *} p<0.001 ;{ }^{* * * *} p<0.0001$.

\subsection{Hexosamine Substrate Transport by FVB and B6 LG-ESC}

If the differential responsiveness of FVB and B6 embryos and LG-ESC to the effects of high glucose is related to differential reliance on exogenous GlcN, this suggests that strains that are less dependent on exogenous GlcN, and less sensitive to the adverse effects of high glucose, would be more dependent on glucose (at physiological concentrations via low $\mathrm{K}_{\mathrm{M}}$ transporters) and glutamine to provide substrates for hexosamine biosynthesis, as well as for growth and energy production. If this is the case, there may be differences in steady state levels of low and high $K_{M}$ glucose transporters (i.e., high and low $K_{M}$ GlcN transporters) and glutamine transporters, and/or functional transport of glucose, glutamine, and GlcN of FVB and B6 LG-ESC that indicate differential substrate utilization. Immunoblots demonstrated that there were several differences in steady state protein levels, both between LG-ESC of either strain at the same stage of differentiation, and between undifferentiated and differentiating neuronal precursors of each strain, of the glucose transporters, GLUT1, GLUT2, and GLUT3, and the glutamine transporters, ASCT2, LAT1, SNAT1, and SNAT5 (Figure 2A). However, the patterns of these differences in protein levels of glucose or glutamine transporters did not explain differential reliance on uptake of GlcN versus uptake of glucose + glutamine between the strains, or at different stages of differentiation. 

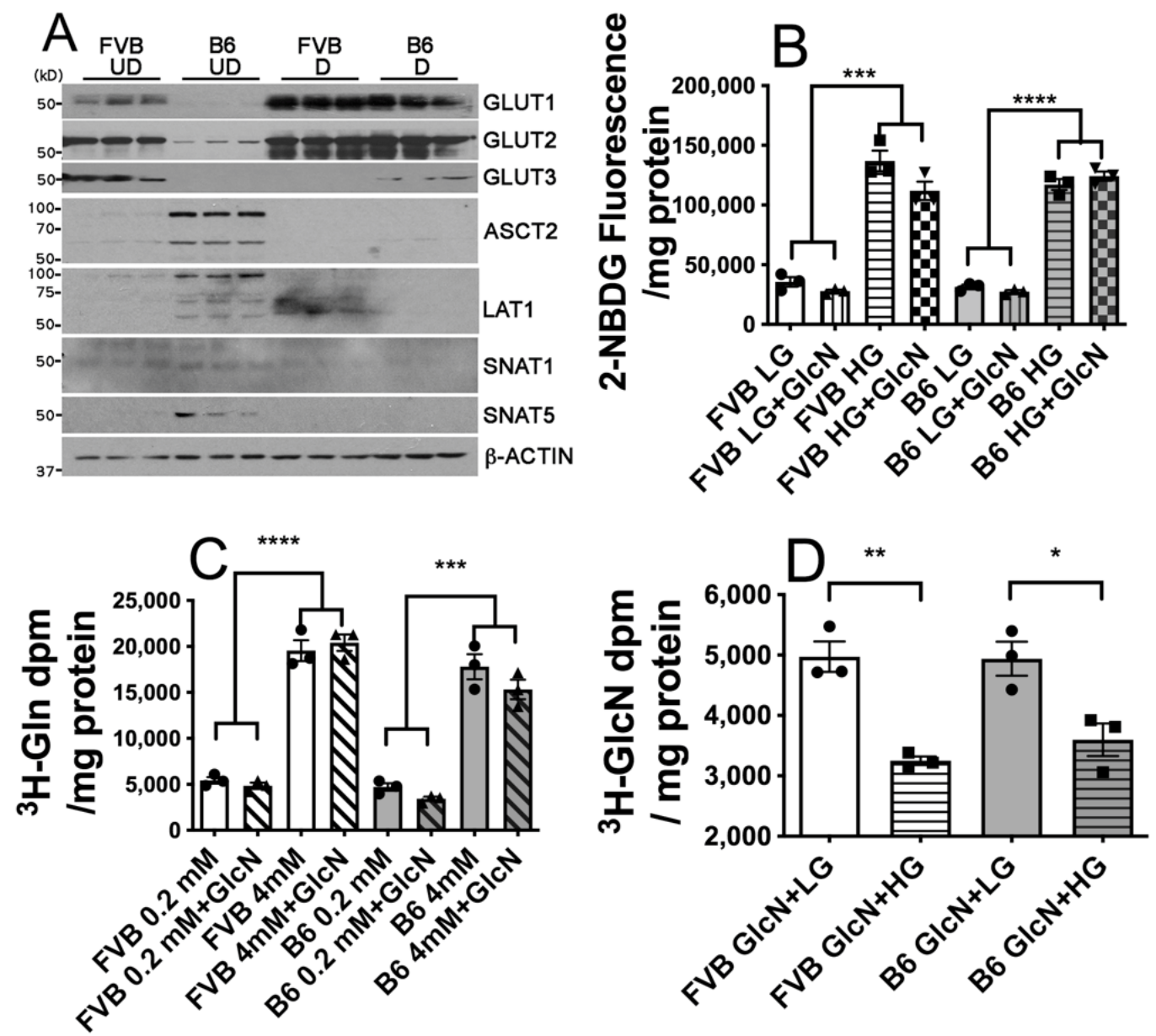

Figure 2. Transport of the hexosamine biosynthetic pathway substrates glucose, glutamine, and GlcN by FVB and B6 LG-ESC. (A) Immunoblot analysis of steady state levels of the glucose transporters, GLUT1 ( 55 kDa), GLUT2 ( 57 kDa), and GLUT3 ( 47 kDa), and the glutamine transporters, ASCT2 ( $56 \mathrm{kDa})$, LAT1 ( $\sim 55 \mathrm{kDa})$, SNAT1 ( 48 kDa), and SNAT5 $(\sim 52 \mathrm{kDa})$, and $\beta$-ACTIN $(\sim 42 \mathrm{kDa})$ as a loading control, from three replicate culture dishes of undifferentiated (UD) or differentiating neuronal precursors (D) from FVB or B6 LG-ESC. (B) Transport of 5 (LG) or 16 mmol/L (HG) fluorescent 2deoxy-D-glucose (2-NBDG) in the presence or absence of $0.8 \mathrm{mmol} / \mathrm{L} \mathrm{GlcN}$. (C) Transport of 0.2 or $4 \mathrm{mmol} / \mathrm{L}^{3} \mathrm{H}$-glutamine (Gln) in the presence or absence of $0.8 \mathrm{mmol} / \mathrm{L} \mathrm{GlcN}$. (D) Transport of $0.8 \mathrm{mmol} / \mathrm{L}^{3} \mathrm{H}-\mathrm{GlcN}$ in the presence or absence of 5 (LG) or $16(\mathrm{HG}) \mathrm{mmol} / \mathrm{L}$ glucose. Data shown are means \pm SEM and were analyzed by two-way ANOVA followed by Tukey's multiple comparisons test $(\mathbf{B}, \mathbf{C})$ or Student $\mathrm{t}$ test (D). ${ }^{*} p<0.05 ;{ }^{* *} p<0.01 ;{ }^{* * *} p<0.001{ }^{* * * *} p<0.0001$.

To investigate whether there are functional differences in the transport of substrates for the hexosamine biosynthetic pathway in FVB and B6 LG-ESC, we assayed uptake of the fluorescent 2-deoxy-D-glucose analog, 2-NBDG (using 5 or $16 \mathrm{mmol} / \mathrm{L}$ to distinguish uptake by low and high $\mathrm{K}_{\mathrm{M}}$ glucose transporters) in the presence or absence of $0.8 \mathrm{mmol} / \mathrm{L}$ GlcN, uptake of ${ }^{3} \mathrm{H}$-glutamine (using 0.2 or $4 \mathrm{mmol} / \mathrm{L}$ to distinguish uptake by low and high $\mathrm{K}_{\mathrm{M}}$ glutamine transporters [26-28]) in the presence or absence of $0.8 \mathrm{mmol} / \mathrm{L} \mathrm{GlcN}$, or uptake of ${ }^{3} \mathrm{H}-\mathrm{GlcN}$ in the presence of 5 or $16 \mathrm{mmol} / \mathrm{L}$ glucose. Transport of $16 \mathrm{mmol} / \mathrm{L}$ 2-NBDG was significantly increased compared to $5 \mathrm{mmol} / \mathrm{L} 2-\mathrm{NBDG}$ by both FVB and B6 LG-ESC (Figure 2B), suggesting that both cell lines express functional GLUT2 transporters. There was no significant inhibition of either 5 or $16 \mathrm{mmol} / \mathrm{L} 2-\mathrm{NBDG}$ uptake by $0.8 \mathrm{mmol} / \mathrm{L}$ GlcN by either cell line, suggesting that availability of exogenous GlcN does not affect transport of glucose by either low or high $\mathrm{K}_{\mathrm{M}}$ glucose transporters. Transport of $4 \mathrm{mmol} / \mathrm{L}$ ${ }^{3} \mathrm{H}$-glutamine was significantly increased compared to $0.2 \mathrm{mmol} / \mathrm{L}^{3} \mathrm{H}$-glutamine by both cell lines, and there was no effect of GlcN on ${ }^{3} \mathrm{H}$-glutamine uptake by either cell line (Figure 2C), suggesting that availability of exogenous GlcN does not affect transport of glutamine by either low- or high- $\mathrm{K}_{\mathrm{M}}$ glutamine transporters. Both FVB and B6 LG-ESC 
transported ${ }^{3} \mathrm{H}-\mathrm{GlcN}$, and transport of ${ }^{3} \mathrm{H}-\mathrm{GlcN}$ was significantly inhibited by $16 \mathrm{mmol} / \mathrm{L}$ glucose in both cell lines (Figure 2D). This indicated that GLUT2 functions as a GlcN transporter for both FVB and B6 LG-ESC, and that high glucose concentrations compete with GlcN for GLUT2-mediated uptake. Nevertheless, there were no functional differences in transport of any of the substrates for the hexosamine biosynthetic pathway by the two cell lines.

\subsection{Protein Glycosylation Substrate Utilization in FVB and B6 LG-ESC}

We next tested whether utilization of glucose, glutamine, and GlcN as substrates for hexosamine biosynthesis by FVB and B6 LG-ESC may differ by assaying the incorporation of ${ }^{3} \mathrm{H}$-glutamine or ${ }^{3} \mathrm{H}-\mathrm{GlcN}$ into (total $\mathrm{N}$ - and $\mathrm{O}$-glycosylated) glycoproteins. GlcN significantly inhibited ${ }^{3} \mathrm{H}$-glutamine incorporation by FVB, but not by B6, LG-ESC (Figure 3A). There was significantly less ${ }^{3} \mathrm{H}-\mathrm{GlcN}$ incorporation by B6 LG-ESC than by FVB LG-ESC (Figure 3B). We further tested whether there were differences in levels of $O$ or $\mathrm{N}$-glycosylation when only glucose + glutamine were available as substrates, or when glucose, glutamine, and GlcN were available. Steady state levels of O-GlcNAcylated proteins were assayed by immunoblot and were increased by supplemental GlcN in both cell lines (Figure 3C). Levels of $\mathrm{N}$-glycosylated proteins were assayed by periodic acid-Schiff (PAS) staining of SDS-polyacrylamide gels and were significantly increased by GlcN in both cell lines; however, the increased glycosylation in FVB LG-ESC was 2.6-fold, and in B6 LG-ESC was only 1.4-fold (Figure 3D,E).

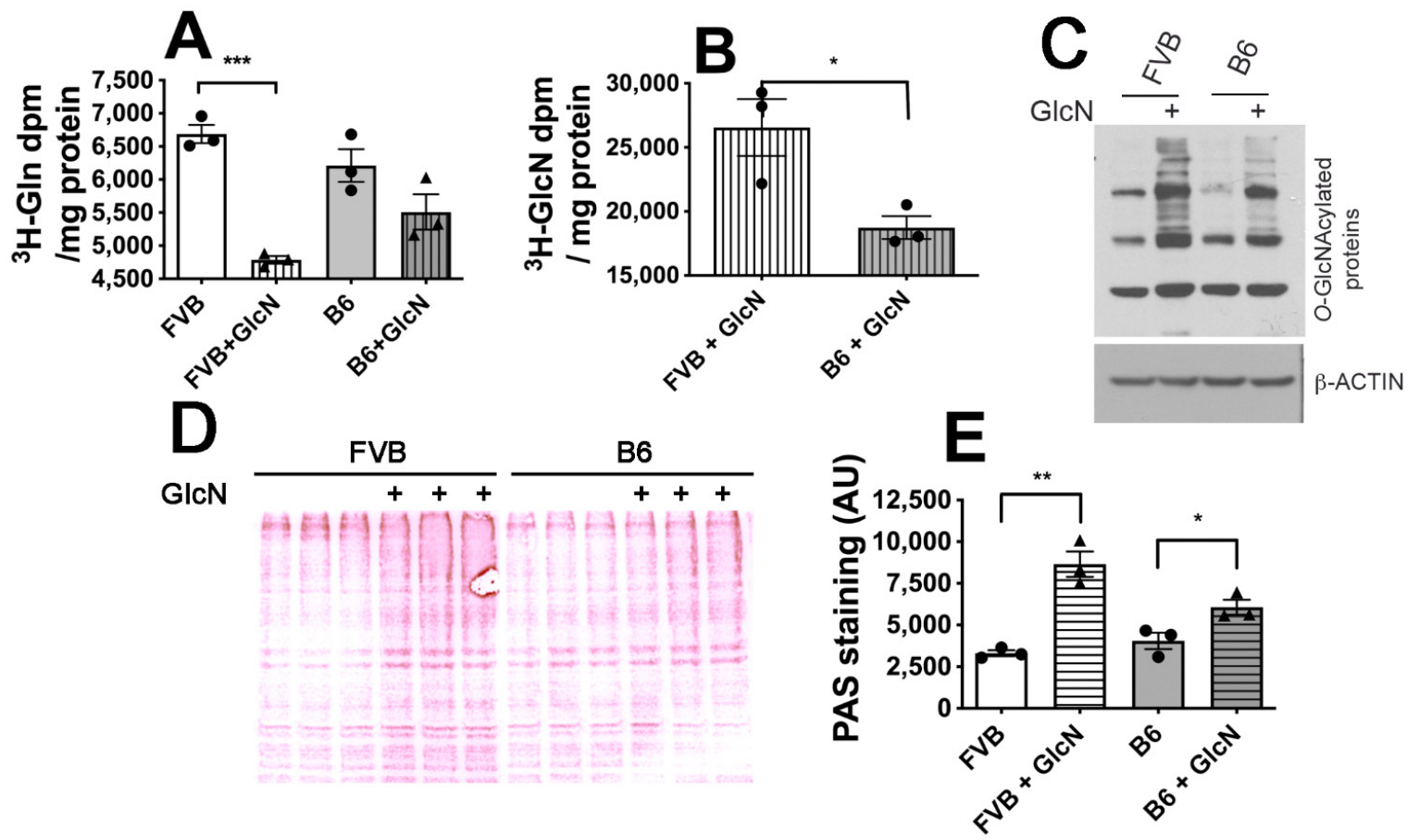

Figure 3. Glycosylation substrate utilization by FVB and B6 LG-ESC. (A) WGA-precipitated glycoproteins labeled with ${ }^{3} \mathrm{H}$-glutamine from FVB and B6 LG-ESC cultured $\pm 0.8 \mathrm{mmol} / \mathrm{L}$ GlcN. (B) WGA-precipitated glycoproteins labeled with ${ }^{3} \mathrm{H}-\mathrm{GlcN}$ from FVB and B6 LG-ESC. (C) Immunoblot of O-GlcNAcylated proteins following culture of FVB or B6 LG-ESC $\pm 0.8 \mathrm{mmol} / \mathrm{L}$ GlcN. (D) Periodic acid-Schiff (PAS) stain of $N$-glycosylated proteins separated by SDS-Polyacrylamide gel electrophoresis from three replicate culture dishes following culture of FVB or B6 LG-ESC $\pm 0.8 \mathrm{mmol} / \mathrm{L} \mathrm{GlcN}$. (E) Quantitation of PAS staining from (D). Data shown are means \pm SEM and were analyzed by Student $\mathrm{t}$ test. ${ }^{*} p<0.05$; ${ }^{* *} p<0.01 ;{ }^{* * *} p<0.001$. 


\subsection{Growth Metabolic Effects of GlcN Uptake in FVB and B6 LG-ESC}

We previously showed that GLUT2-transported GlcN stimulates growth and proliferation of FVB LG-ESC, which appears to result from decreased flux of fructose-6- $\mathrm{PO}_{4}+$ glutamine into the HBP, thereby increasing levels of glycolytic intermediates and glutamine that can be used for biomass accumulation and for maintaining energy production [18]. With decreased flux of fructose-6- $\mathrm{PO}_{4}$ into the HBP, there is increased accumulation of glucose-6- $\mathrm{PO}_{4}$, which stimulates activity of the PPP [18], thereby increasing substrates for nucleotide synthesis, as well as NADPH to increase reduction of the antioxidant, reduced glutathione (GSH) from oxidized glutathione (GSSG).

To test whether B6 LG-ESC and embryos are less dependent on GlcN for stimulation of growth and the PPP than FVB LG-ESC and embryos, we cultured FVB or B6 LGESC with or without GlcN and counted numbers of alkaline phosphatase-positive (i.e., pluripotent) colonies, and assayed (glucose-6-phosphate dehydrogenase) G6PD activity, the rate-controlling enzyme of the PPP. GlcN significantly increased numbers of alkaline phosphatase-positive FVB LG-ESC colonies, as observed previously [18], but there was no effect of GlcN on B6 LG-ESC colonies (Figure 4A). Notably, GlcN significantly stimulated G6PD activity in FVG LG-ESC, but had no effect on G6PD activity in B6 LG-ESC (Figure 4B). As a consequence of stimulation of the PPP by GLUT2-transported GlcN in FVB, but not B6, embryo cells, we considered that there may be increased oxidative stress in response to high glucose in FVB, but not B6 embryo cells. In support of this, high glucose media increased levels of malondialdehyde, a marker of oxidative stress, by FVB LG-ESC, but not by B6 LG-ESC (Figure 4C).
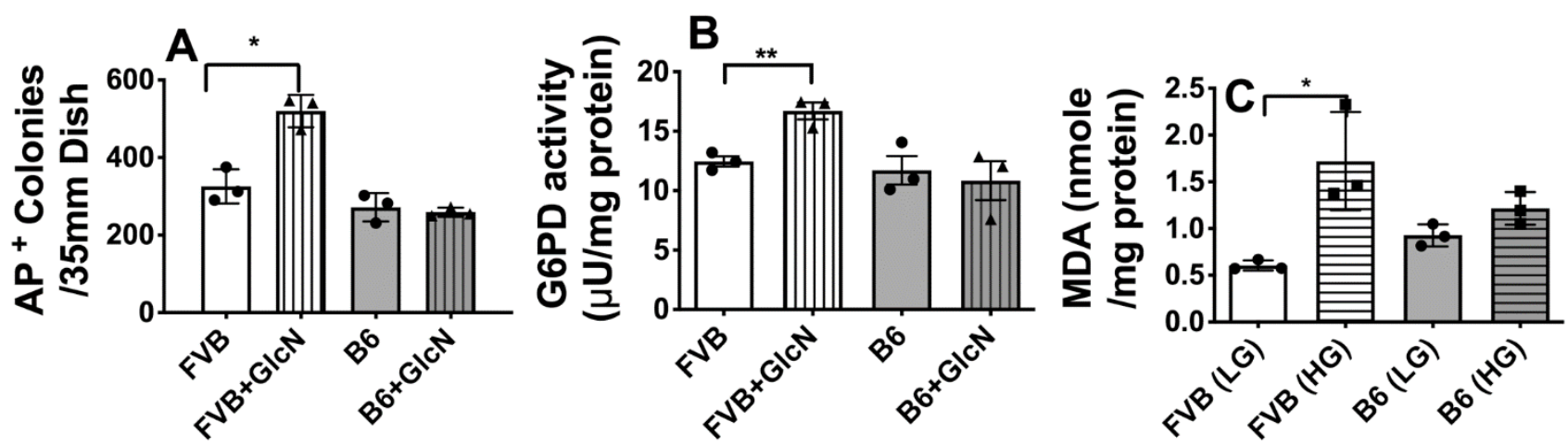

Figure 4. Relationships between differences in GlcN utilization on GlcN stimulation of growth, pentose phosphate pathway (PPP) activities, and high glucose-induced oxidative stress between FVB and B6 LG-ESC. (A) Alkaline phosphatase-positive $(\mathrm{AP}+)$ colonies following culture in low glucose media $\pm 0.8 \mathrm{mmol} / \mathrm{L}$ GlcN. (B) G6PD enzyme activity by FVB and B6 LG-ESC cultured $\pm 0.8 \mathrm{mmol} / \mathrm{L}$ GlcN. (C) Intracellular malondialdehyde (MDA) concentrations in FVB or B6 LG-ESC cultured for $8 \mathrm{~h}$ in low or high glucose media. Data shown are means \pm SEM and were analyzed by Student $\mathrm{t}$ test (B) * $p<0.05 ;{ }^{* *} p<0.01$.

\section{Discussion}

We previously showed that $\mathrm{B} 6$ embryos are resistant to diabetic embryopathy, compared to FVB embryos [19]. The data presented here show that B6 embryos are specifically resistant to maternal hyperglycemia just prior to induction of neural tube formation, independent of other metabolic disturbances of diabetes, and this is not due to differences in expression of Glut2 mRNA, which encodes the high $\mathrm{K}_{\mathrm{M}}$ glucose transporter that is required for susceptibility to hyperglycemia-induced NTDs [5]. High glucose culture inhibited expression of $P a x 3$, a gene whose inhibition leads to diabetic pregnancy-induced NTDs $[13,19]$, by LG-ESC derived from FVB, but not B6 embryos, even though expression of Glut2 by these cell lines does not differ. This demonstrated that FVB and B6 LG-ESC can be used to study the differential susceptibility of these strains to the adverse embryonic effects of high glucose. An in vitro model is essential to investigate whether the differen- 
tial susceptibility of these strains is related to GlcN transport or metabolism because it is not possible to eliminate or lower maternal GlcN concentrations, and efforts to raise maternal GlcN by supplemental administration would increase high $\mathrm{K}_{\mathrm{M}}$ GlcN transport by GLUT1 [17].

There were no differences between GlcN transport by FVB or B6 LG-ESC, or of the other substrates that can be used for hexosamine biosynthesis, glucose, and glutamine. As observed previously for FVB LG-ESC [18], GLUT2-transported glucose significantly inhibited uptake of GlcN by both cell lines. While this supports the possibility that the adverse effects of high glucose might not just be due to increased glucose uptake, but also due to decreased GlcN uptake, it does not explain the insensitivity of B6 embryo and ESC to the adverse effects of high glucose. However, differences in ${ }^{3} \mathrm{H}$-glutamine and ${ }^{3} \mathrm{H}-\mathrm{GlcN}$ incorporation into WGA-precipitable protein suggests that FVB LG-ESC utilize exogenous GlcN over fructose-6- $-\mathrm{PO}_{4}+$ glutamine for glycosylations compared to B6 LG-ESC. By utilizing exogenous GlcN for the HPB, glycolytic intermediates and glutamine in FVB LGESC are spared and can be used for biomass accumulation and stimulation of the PPP. Thus, when there is increased GLUT2-transported glucose (and less GLUT2-transported GlcN) by FVB LG-ESC, there is less generation of NADPH, leading to increased oxidative stress. We previously suggested that GlcN may be an essential nutrient for embryos because they cannot synthesize sufficient amounts of HBS substrate from fructose-6- $\mathrm{PO}_{4}+$ glutamine without compromising biomass accumulation [18]. Our data suggest that GlcN may not be essential for all mouse strains. While $\mathrm{O}$ - and $\mathrm{N}$-glycosylations were increased by GlcN in B6 LG-ESC, growth, and substrates derived from the PPP, were not inhibited in B6 LG-ESC in the absence of exogenous GlcN.

Of note, if $\mathrm{B} 6$ embryos and ESC are more reliant on fructose-6- $\mathrm{PO}_{4}+$ glutamine, than on GlcN, for GlcN-6- $\mathrm{PO}_{4}$ production, this would cause increased glutamate production, which may lead to increased GSH synthesis [29]. This could further protect B6 embryos and ESC from high glucose-induced oxidative stress.

There have been some reports that stimulation of $O-G 1 c N A c$ transferase, which catalyzes $\mathrm{O}$-linked glycosylation of serine and threonine residues with UDP-N-Acetyl-GlcN, by GlcN promotes proliferation of murine ESC [30-32]. There was also a recent report that proliferation of mouse embryo fibroblasts (MEFs) requires noncatalytic functions of O-GlcNAc transferase [33]. However, the ESC and MEF lines used in those studies were isolated under conventional high glucose conditions and would not express GLUT2, and the ESC were treated with GlcN at concentrations that would be transported by GLUT1 [17]. Using our FVB LG-ESC, we found that there is no effect of GlcN to stimulate pluripotency or to inhibit differentiation, and inhibiting O-GlcNAc transferase activity or knocking down its expression with shRNA showed that stimulation of proliferation by GlcN is not due to increased O-GlcNAc transferase activity [18]. Rather, stimulation of proliferation by GlcN appears to be due to increased availability of glycolytic intermediates and glutamine for biomass accumulation [18].

Kim, et al. reported that an $\mathrm{O}-\mathrm{GlcNAc}$ transferase inhibitor reduced NTDs and alleviated oxidative stress in embryos of diabetic mice, suggesting that increased O-linked glycosylation in response to maternal hyperglycemia contributes to diabetic embryopathy [34]. However, we showed that NTDs induced by maternal hyperglycemia or administration of GlcN (at concentrations that would be transported by GLUT1) were prevented by supplemental GSH [24]. It is possible that the effect O-GlcNAc transferase inhibition in embryos of diabetic mice by Kim, et al. caused HBP intermediates upstream of UDP-N-Acetyl-GlcN, including GlcN-6- $\mathrm{PO}_{4}$, to accumulate, and consequently, to increase glycolytic intermediates, including glucose-6- $\mathrm{PO}_{4}$, leading to stimulation of the PPP. Thus, increased NADPH, rather than decreased protein $O$-linked glycosylation, may be the mechanism for decreased oxidative stress and NTDs caused by the O-GlcNAc transferase inhibitor.

We recognize that resistance of the B6 strain to diabetic embryopathy that is observed by us and by some other laboratories (personal communication) is not observed by some other groups that have used the $\mathrm{C} 57 \mathrm{Bl} / 6 \mathrm{~J}$ or $\mathrm{C} 57 \mathrm{Bl} / 6 \mathrm{CrJ}$ strains in the study of diabetic 
embryopathy [35-37]. In the studies in which C57Bl/6J or C57Bl/6CrJ strains have been successfully employed, the subcutaneously-implanted insulin pellets that we found are essential to prevent severe hyperglycemia and pregnancy loss in the periimplantation period [13] either were not used, or were surgically removed after implantation, so the glucotoxicity may be more severe than that to which our mice are subjected [35-37]. There could be other procedural, dietary, or environmental variations in different laboratory settings that might influence penetrance of malformations in B6 diabetic pregnancies. Nonetheless, the same high glucose concentrations that induced oxidative stress, which has been shown to play a causal role diabetic embryopathy in several animal studies [7-12], in FVB LG-ESC, did not induce oxidative stress in B6 LG-ESC. This indicates that there are genetic background differences between the two mouse strains in their responsiveness to the elevated glucose concentrations that occur during maternal diabetes.

There are some limitations of this study that should be recognized. For example, we did not test whether stimulation of the PPP by GlcN, and consequently, increased reduction of GSH from GSSG, is inhibited by high glucose in FVB LG-ESC, although these experiments are currently underway in our laboratory. Although a cell culture model of embryonic neuroepithelium is valuable to study the biochemical and molecular processes that lead to NTDs in diabetic embryopathy, it does not model the physical processes associated with convergent extension that occur during neural tube closure which could be affected by maternal diabetes. On the other hand, we have shown that high glucose does not inhibit LG-ESC to form 3-D neural cysts, which have been shown by others to model neural tube formation [38,39], so this may not be a shortcoming of our 2-D cell culture model. This study only examined effects of GlcN utilization and high glucose-induced oxidative stress by ESC that give rise to neuronal precursors, but we did not examine whether these processes are affected in other cell types that are prone to malformation in diabetic pregnancy, such as cardiac progenitors. Finally, although study GlcN metabolism, incorporation, and oxidative stress in intact FVB and B6 embryos is desirable, it is not possible to lower or eliminate GlcN in vivo, as explained previously. However, metabolomic profiling using dense isotopologues of $\mathrm{GlcN}$, glucose, and glutamine administered to the pregnant mothers may make it possible to obtain further information on the role of GlcN on diabetic embryopathy in vivo.

\section{Conclusions}

The data reported here suggest that differential effects of GlcN on G6PD, the ratecontrolling enzyme of the PPP, and therefore, on production of NADPH, with its consequent regulation of antioxidant capacity, may be responsible for the differential susceptibility of FVB and B6 embryos to diabetic embryopathy. Further investigation is needed to better understand GlcN metabolism during normal and high glucose conditions on different genetic backgrounds, and whether any differential GlcN-dependent pathways might be amenable for therapeutic intervention.

Author Contributions: Conceptualization, M.R.L.; methodology, J.H.J. and M.R.L.; validation, J.H.J. and M.R.L.; formal analysis, J.H.J. and M.R.L.; investigation, J.H.J.; writing-original draft preparation, M.R.L.; writing-review and editing, M.R.L.; visualization, J.H.J. and M.R.L.; supervision, M.R.L.; project administration, M.R.L.; funding acquisition, M.R.L. All authors have read and agreed to the published version of the manuscript.

Funding: This research was funded by the National Institutes of Health, grant numbers R01DK058300 and R01DK104649 (to M.R.L.) and P30DK036836 (to the Joslin Diabetes Center).

Institutional Review Board Statement: The study was approved by the Institutional Animal Care and Use Committee of the Joslin Diabetes Center (protocol \#92-06, approved June 1992).

Informed Consent Statement: Not applicable.

Data Availability Statement: Data is contained within the article.

Acknowledgments: The authors thank Zhihong Yang (JDC) for assistance with G6PD assays. 
Conflicts of Interest: The authors declare no conflict of interest. The funder of this research had no role in the design of the study; in the collection, analyses, or interpretation of data; in the writing of the manuscript, or in the decision to publish the results.

\section{References}

1. Kucera, J. Rate and type of congenital anomalies among offspring of diabetic women. J. Reprod. Med. 1971, 7, 61-70.

2. Correa, A.; Gilboa, S.M.; Besser, L.M.; Botto, L.D.; Moore, C.A.; Hobbs, C.A.; Cleves, M.A.; Riehle-Colarusso, T.J.; Waller, D.K.; Reece, E.A. Diabetes mellitus and birth defects. Am. J. Obstet. Gynecol. 2008, 199, 237.e1-237.e9. [CrossRef]

3. Evers, I.M.; de Valk, H.W.; Visser, G.H. Risk of complications of pregnancy in women with type 1 diabetes: Nationwide prospective study in the Netherlands. BMJ 2004, 328, 908-915. [CrossRef]

4. Loeken, M.R. Mechanisms of Congenital Malformations in Pregnancies with Pre-existing Diabetes. Curr. Diabetes Rep. 2020, 20, 54. [CrossRef] [PubMed]

5. Li, R.; Thorens, B.; Loeken, M.R. Expression of the gene encoding the high Km glucose transporter 2 by the early postimplantation mouse embryo is essential for neural tube defects associated with diabetic embryopathy. Diabetologia 2007, 50, 682-689. [CrossRef] [PubMed]

6. Fine, E.; Horal, M.; Chang, T.; Fortin, G.; Loeken, M. Evidence that hyperglycemia causes altered gene expression, apoptosis, and neural tube defects in a mouse model of diabetic pregnancy. Diabetes 1999, 48, 2454-2462. [CrossRef] [PubMed]

7. Siman, C.M.; Eriksson, U.J. Vitamin E decreases the occurrence of malformations in the offspring of diabetic rats. Diabetes 1997, 46, 1054-1061. [CrossRef]

8. Sivan, E.; Reece, E.A.; Wu, Y.K.; Homko, C.J.; Polansky, M.; Borenstein, M. Dietary vitamin E prophylaxis and diabetic embryopathy: Morphologic and biochemical analysis. Am. J. Obstet. Gynecol. 1996, 175, 793-799. [CrossRef]

9. Viana, M.; Herrera, E.; Bonet, B. Terotogenic effects of diabetes mellitus in the rat. Prevention by vitamin E. Diabetologia 1996, 39, 1041-1046. [CrossRef]

10. Hagay, Z.J.; Weiss, Y.; Zusman, I.; Peled-Kamar, M.; Reece, E.A.; Eriksson, U.J.; Groner, Y. Prevention of diabetes-associated embryopathy by overexpression of the free radical scavenger copper zinc superoxide dismutase in transgenic mouse embryos. Am. J. Obstet. Gynecol. 1995, 173, 1036-1041. [CrossRef]

11. Yang, P.; Zhao, Z.; Reece, E.A. Activation of oxidative stress signaling that is implicated in apoptosis with a mouse model of diabetic embryopathy. Am. J. Obstet. Gynecol. 2008, 198, 130.e1-130.e7. [CrossRef] [PubMed]

12. Chang, T.I.; Horal, M.; Jain, S.K.; Wang, F.; Patel, R.; Loeken, M.R. Oxidant regulation of gene expression and neural tube development: Insights gained from diabetic pregnancy on molecular causes of neural tube defects. Diabetologia 2003, 46, 538-545. [CrossRef] [PubMed]

13. Phelan, S.A.; Ito, M.; Loeken, M.R. Neural tube defects in embryos of diabetic mice: Role of the Pax-3 gene and apoptosis. Diabetes 1997, 46, 1189-1197. [CrossRef] [PubMed]

14. Pani, L.; Horal, M.; Loeken, M.R. Rescue of neural tube defects in Pax-3-deficient embryos by p53 loss of function: Implications for Pax-3- dependent development and tumorigenesis. Genes Dev. 2002, 16, 676-680. [CrossRef] [PubMed]

15. Hogan, A.; Heyner, S.; Charron, M.J.; Copeland, N.G.; Gilbert, D.J.; Jenkins, N.A.; Thorens, B.; Schultz, G.A. Glucose transporter gene expression in early mouse embryos. Development 1991, 113, 363-372. [CrossRef]

16. Matsumoto, K.; Akazawa, S.; Ishibashi, M.; Trocino, R.A.; Matsuo, H.; Yamasaki, H.; Yamaguchi, Y.; Nagamatsu, S.; Nagataki, S. Abundant expression of GLUT1 and GLUT3 in rat embryo during the early organogenesis period. Biochem. Biophys. Res. Commun. 1995, 209, 95-102. [CrossRef] [PubMed]

17. Uldry, M.; Ibberson, M.; Hosokawa, M.; Thorens, B. GLUT2 is a high affinity glucosamine transporter. FEBS Lett. 2002, 524, 199-203. [CrossRef]

18. Jung, J.H.; Iwabuchi, K.; Yang, Z.; Loeken, M.R. Embryonic Stem Cell Proliferation Stimulated By Altered Anabolic Metabolism From Glucose Transporter 2-Transported Glucosamine. Sci. Rep. 2016, 6, 28452. [CrossRef]

19. Pani, L.; Horal, M.; Loeken, M.R. Polymorphic susceptibility to the molecular causes of neural tube defects during diabetic embryopathy. Diabetes 2002, 51, 2871-2874. [CrossRef]

20. Wang, F.; Thirumangalathu, S.; Loeken, M.R. Establishment of new mouse embryonic stem cell lines is improved by physiological glucose and oxygen. Cloning Stem Cells 2006, 8, 108-116. [CrossRef]

21. Jung, J.H.; Wang, X.D.; Loeken, M.R. Mouse embryonic stem cells established in physiological-glucose media express the high KM Glut2 glucose transporter expressed by normal embryos. Stem cells Transl. Med. 2013, 2, 929-934. [CrossRef]

22. Wu, Y.; Viana, M.; Thirumangalathu, S.; Loeken, M.R. AMP-activated protein kinase mediates effects of oxidative stress on embryo gene expression in a mouse model of diabetic embryopathy. Diabetologia 2012, 55, 245-254. [CrossRef]

23. Wang, X.D.; Morgan, S.C.; Loeken, M.R. Pax3 stimulates p53 ubiquitination and degradation independent of transcription. PLoS ONE 2011, 6, e29379. [CrossRef]

24. Horal, M.; Zhang, Z.; Stanton, R.; Virkamaki, A.; Loeken, M.R. Activation of the hexosamine pathway causes oxidative stress and abnormal embryo gene expression: Involvement in diabetic teratogenesis. Birth Defects Res. A Clin. Mol. Teratol. 2004, 70, 519-527. [CrossRef] 
25. Tian, W.N.; Pignatare, J.N.; Stanton, R.C. Signal transduction proteins that associate with the platelet-derived growth factor (PDGF) receptor mediate the PDGF-induced release of glucose-6-phosphate dehydrogenase from permeabilized cells. J. Biol. Chem. 1994, 269, 14798-14805. [CrossRef]

26. Bode, B.P. Recent molecular advances in mammalian glutamine transport. J. Nutr. 2001, 131, 2475S-2485S. [CrossRef] [PubMed]

27. Baird, F.E.; Beattie, K.J.; Hyde, A.R.; Ganapathy, V.; Rennie, M.J.; Taylor, P.M. Bidirectional substrate fluxes through the system N (SNAT5) glutamine transporter may determine net glutamine flux in rat liver. J. Physiol. 2004, 559, 367-381. [CrossRef]

28. Lewis, A.M.; Kaye, P.L. Characterization of glutamine uptake in mouse two-cell embryos and blastocysts. Reproduction 1992, 95, 221-229. [CrossRef] [PubMed]

29. Neu, J.; Shenoy, V.; Chakrabarti, R. Glutamine nutrition and metabolism: Where do we go from here? FASEB J. 1996, 10, 829-837. [CrossRef] [PubMed]

30. Jang, H.; Kim, T.W.; Yoon, S.; Choi, S.Y.; Kang, T.W.; Kim, S.Y.; Kwon, Y.W.; Cho, E.J.; Youn, H.D. O-GlcNAc regulates pluripotency and reprogramming by directly acting on core components of the pluripotency network. Cell Stem Cell 2012, 11, 62-74. [CrossRef]

31. Jeon, J.H.; Suh, H.N.; Kim, M.O.; Han, H.J. Glucosamine-induced reduction of integrin beta4 and plectin complex stimulates migration and proliferation in mouse embryonic stem cells. Stem Cells Dev. 2013, 22, 2975-2989. [CrossRef] [PubMed]

32. Jeon, J.H.; Suh, H.N.; Kim, M.O.; Ryu, J.M.; Han, H.J. Glucosamine-induced OGT activation mediates glucose production through cleaved Notch1 and FoxO1, which coordinately contributed to the regulation of maintenance of self-renewal in mouse embryonic stem cells. Stem Cells Dev. 2014, 23, 2067-2079. [CrossRef] [PubMed]

33. Levine, Z.G.; Potter, S.C.; Joiner, C.M.; Fei, G.Q.; Nabet, B.; Sonnett, M.; Zachara, N.E.; Gray, N.S.; Paulo, J.A.; Walker, S. Mammalian cell proliferation requires noncatalytic functions of O-GlcNAc transferase. Proc. Natl. Acad. Sci. USA 2021, 118. [CrossRef] [PubMed]

34. Kim, G.; Cao, L.; Reece, E.A.; Zhao, Z. Impact of protein O-GlcNAcylation on neural tube malformation in diabetic embryopathy. Sci. Rep. 2017, 7, 11107. [CrossRef] [PubMed]

35. Wang, F.; Reece, E.A.; Yang, P. Superoxide dismutase 1 overexpression in mice abolishes maternal diabetes-induced endoplasmic reticulum stress in diabetic embryopathy. Am. J. Obstet. Gynecol. 2013, 209, 345.e1-345.e7. [CrossRef] [PubMed]

36. Zhao, Z.; Yang, P.; Eckert, R.L.; Reece, E.A. Caspase-8: A key role in the pathogenesis of diabetic embryopathy. Birth Defects Res. B Dev. Reprod. Toxicol. 2009, 86, 72-77. [CrossRef] [PubMed]

37. Kamimoto, Y.; Sugiyama, T.; Kihira, T.; Zhang, L.; Murabayashi, N.; Umekawa, T.; Nagao, K.; Ma, N.; Toyoda, N.; Yodoi, J.; et al. Transgenic mice overproducing human thioredoxin-1, an antioxidative and anti-apoptotic protein, prevents diabetic embryopathy. Diabetologia 2010, 53, 2046-2055. [CrossRef]

38. Sanders, K.; Jung, J.H.; Loeken, M.R. Use of a murine embryonic stem cell line that is sensitive to high glucose environment to model neural tube development in diabetic pregnancy. Birth Defects Res. Part A Clin. Mol. Teratol. 2014, 100, 584-591. [CrossRef]

39. Meinhardt, A.; Eberle, D.; Tazaki, A.; Ranga, A.; Niesche, M.; Wilsch-Brauninger, M.; Stec, A.; Schackert, G.; Lutolf, M.; Tanaka, E.M. 3D reconstitution of the patterned neural tube from embryonic stem cells. Stem Cell Rep. 2014, 3, 987-999. [CrossRef] 